quan tâm tới những thú vui, sở thích trước đây.

3.2.4. Triệu chứng phổ biến của trâm cảm theo ICD10

Bảng 5. Triệu chứng phổ biên của trâm caim theo ICD10 $(N=35)$

\begin{tabular}{|c|c|c|}
\hline Triệu chứng $\quad$ Số lượng & $\mathbf{n}$ & $\%$ \\
\hline Giảm tập trung chú ý & 10 & 28,6 \\
\hline $\begin{array}{l}\text { Giảm sút tính tự trọng và } \\
\text { lòng tự tin }\end{array}$ & 33 & 94,3 \\
\hline $\begin{array}{l}\text { Y tưởng bị tội và không xứng } \\
\text { đáng }\end{array}$ & 10 & 28,6 \\
\hline Bi quan về tương lai & 33 & 94,3 \\
\hline Y tưởng hoăc hành vi tư sát & 7 & 20 \\
\hline Rối loan giấc nqủ & 30 & 85,7 \\
\hline Ăn ít ngon miêng & 19 & 54,3 \\
\hline
\end{tabular}

Nhận xét: Trong số các triệu chứng phổ biến của trẩm cảm theo ICD10, giảm sút tính tự trọng, lòng tự tin và bi quan về tương lai là hai triệu chứng hay gặp nhất với cùng tỷ lệ 94,3\%. Rối loạn giấc ngủ cũng thường xuyên xuất hiện $(85,7 \%)$. Các triệu chứng khác lần lượt là ăn ít ngon miệng $(54,3 \%)$, giảm sút tập trung chú ý $(28,6 \%)$, ý tưởng bị tội và không xứng đáng $(28,6 \%)$. Nhìn chung, các triệu chứng phổ biến hay xuất hiên do bênh nhân mắc cảm, tự ti về bản thân, không còn cảm thấy tự tin sau khi bản thân không thể đi lại, vận động được như trước, cảm thấy bi quan về tương lai sau này không thể làm việc sinh hoạt như bình thường được nữa, có thể trở thành gánh nặng cho gia đình và xã hội.

\section{KẾT LUẬN}

Trầm cảm là rối loan tâm thần thường gă̆p ở người bệnh chấn thương tuỷ sống $(32,7 \%)$. Trầm cảm thường khởi phát đầu tiên bởi buồn chán, bi quan (40\%), triệu chứng đặc trưng hay gặp nhất là khí sắc trầm (100\%), triệu chứng phổ biến hay gặp là giảm sút tính tự trọng, lòng tự tin và bi quan về tương lai $(94,3 \%)$.

\section{TÀI LIÊU THAM KHẢO}

1. Khazaeipour Z, Taheri-Otaghsara S-M, Naghdi M. Depression Following Spinal Cord Injury: Its Relationship to Demographic and Socioeconomic Indicators. Top Spinal Cord Inj Rehabil. 2015;21(2):149-155. doi:10.1310/ sci2102-149

2. Psychological Morbidity and Chronic Disease Among Adults With Traumatic Spinal Cord Injuries - Mayo Clinic Proceedings. Accessed August 27, $2021 . \quad$ https://www. mayoclinicproceedings.org/ article/S0025-6196(19) 31094-8/fulltext

3. World Health Organization. Spinal cord injury. Accessed June 4, 2020. https://www.who.int/ news-room/fact-sheets/detail/spinal-cord-injury

4. Depression and Other Common Mental Disorder. Accessed August 27, 2021. https://apps.who.int/iris/bitstream/handle/10665/2 54610/WHO-MSD-MER-2017.2-eng.pdf

5. Kraft R, Dorstyn D. Psychosocial correlates of depression following spinal injury: A systematic review. J Spinal Cord Med. 2015;38(5):571-583. doi: $10.1179 / 2045772314 Y .0000000295$

6. Migliorini C, Tonge B, Taleporos G. Spinal Cord Injury and Mental Health. Aust N Z J Psychiatry. 2008;42(4):309-314. doi:10.1080/ 00048670801886080

\title{
TÌNH HÌNH TRIỂN KHAI HƯỚNG DẪN CHƯƠNG TRÌNH QUẢN LÝ KHÁNG SINH CỦA Bộ Y TẾ Ở CÁC CƠ SỞ Y TẾ TẠI TP. HỒ CHÍ MINH
}

\author{
Nguyễn Thị Hải Yến ${ }^{1}$, Huỳnh Phương Thảo ${ }^{2}$ Lê Đặng Tú Nguyên ${ }^{1}$, \\ Bạch Hoàng Hải Triều ${ }^{1}$, Trần Đình Trung ${ }^{3}$, Lê Ngọc Danh ${ }^{4}$, \\ Trương Văn Đạt ${ }^{1}$, Nguyễn Văn Vĩnh Châu ${ }^{4}$
}

\section{TÓM TẮT}

Mục tiêu: Khảo sát tình hình triển khai chương trình Q QLKS tai các cơ sở y tế trên đia bàn TPHCM năm 2020. Đối tượng và phương pháp nghiên cứu:

\footnotetext{
${ }^{1}$ Đại học Y Dược thành phố Hồ Chí Minh;

²Bênh viện Bệnh Nhiệt đới;

${ }^{3}$ Trường Đại học Kỹ thuât Y-Dước Đà Nẵng

${ }^{4}$ Sở Y tế thành phố Hồ Chí Minh.

Chịu trách nhiệm chính: Nguyễn Thị Hải Yến

Email: haiyen@ump.edu.vn

Ngày nhận bài: 9.7.2021

Ngày phản biên khoa họ: 3.9.2021

Ngày duyệt bài: 10.9.2021
}

Nghiên cứu mô tả cắt ngang khảo sát các cơ sở y tế trên đia bàn TPHCM về việc triển khai chương trình quản lý sử dụng kháng sinh. Kết quả: Tình hình triển khai hoạt động quản lý sử dụng kháng sinh tại 57 cơ sở y tế trên đia bàn TPHCM đat mức trên trình bình với điểm tổng thể là 63/100. Có 48/57 cơ sở đã thực hiên triển khai, trong đó 47/48 cơ sở triển khai theo Quyết định số 772/QĐ-BYT. Chuyên gia về dịch tễ và công nghê thông tin còn thiếu. Hoat động về báo cáo tình hình k̇háng thuốc, cảnh báo trùng thuốc, theo dõi tỷ lệ nhiêm C.difficile chưa được triển khai thường xuyển. Chỉ có 1 trên 7 tiêu chí được trên $70 \%$ cơ sỏ thực hiên, ba tiêu chí về tỷ lệ chuyển kháng sinh tiêm sang uống $(30 \%)$, DOT $(40 \%)$ và DDD $(49 \%)$ được nhìn nhân là khó thưc hiên. Đa số viêc phân tích các tiêu chí mới ở mức độ thử công. Kết luận: Cơ sở y tế 
cần phát huy cơ chế tự chủ để huy động nguồn ngân sách cho hoạt động quản lý kháng sinh và thu hút chuyên gia. Ngoài ra, cơ quan quản lý cần đưa ra các hướng dẫn cụ thể hơn vê các tiêu chí đánh giá và đồng thời cần nghiên cứu ứng dụng công nghệ thông tin để tự động hóa việc phân tích các tiêu chí.

Tư khóa: triển khai hướng dẫn, chương trình quản lý kháng sinh.

\section{SUMMARY}

THE SITUATION OF IMPLEMENTATION OF THE MANAGEMENT PROGRAM GUIDELINES OF THE MINISTRY OF HEALTH IN HEALTH FACILITIES IN HO CHI MINH CITY

Objective: To survey the implementation of the antimicrobial stewardship program at medical facilities in Ho Chi Minh City by 2020. Subjects and methods: Study cross-sectional descriptive survey of medical facilities in Ho Chi Minh City on antimicrobial stewardship program implementation. Results: The implementation of antimicrobial stewardship program in 57 medical facilities in Ho Chi Minh City was above average with an overall score of 63/100. 48/57 establishments have implemented, of which $47 / 48$ establishments have implemented it according to Decision No. 772/QD-BYT. There is a lack of specialists in epidemiology and information technology. Activities of reporting drug resistance, warning of drug duplicated, and monitoring C.difficile infection rates have not been regularly implemented. Only 1 out of 7 indicators/metrics was implemented by more than $70 \%$ of establishments, three indicators/metrics on the rate of switching to oral antibiotics (30\%), DOT $(40 \%)$ and DDD (49\%) were considered to be difficult in analysis. Much of the analysis of the new indicators/metrics is manual. Conclusion: Health facilities need to promote autonomy mechanisms to mobilize budget for antibiotic management activities and attract experts. In addition, the regulator needs to give more specific guidance on the evaluation criteria and at the same time need to study and apply information technology to automate the analysis of the criteria.

Keywords: implementation of guidelines, antibiotic management program.

\section{I. ĐẶT VẤN ĐỀ}

Hiện nay, tỷ lệ đề kháng kháng sinh ở Việt Nam nằm trong vùng cao nhất của Châu Á và Việt Nam có tỷ lệ Streptococcus pneumoniae (nguyên nhân nhiểm trùng đường hô hấp rất phổ biến) kháng penicillin (71,4\%) và kháng erythromycin $(92,1 \%)$ cao nhất trong 11 quốc gia thuộc Mạng lưới châu Á về giám sát mâm bệnh đề kháng (ANSORP) trong năm 2000-2001. Đồng thời, 75\% Pneumococci được ghi nhận là kháng ba nhóm kháng sinh trở lên. [1] Một nghiên cứu được công bố năm 2009 đã báo cáo rằng có $42 \%$ vi khuẩn gram âm đề kháng ceftazidine, $63 \%$ đề kháng gentamicin, và $74 \%$ đề kháng acid nalidixic trong cả bệnh viện và cộng đồng. Trước thực trạng trên, năm 2013, Bộ Y Tế phê duyệt quyết định "Kế hoạch hành động quốc gia về chống kháng thuốc giai đoạn từ năm 2013 đến năm 2020" nhằm giảm thiểu tỉ lệ để kháng kháng sinh. Để hướng dẫn thực hiện chương trình quản lý sử dụng kháng sinh tại bệnh viện (QLKS), Bộ Y tế ban hành Quyết định số 772/QĐ-BYT và tài liệu hướng dẫn thực hiện. Vào ngày 31/12/2020, Bộ Y Tế đã ban hành Quyết định số 5631/QĐ-BY̛T (thay thế cho quyết định trước đó) Hướng dẫn thực hiện quản lý sử dụng kháng trong bệnh viện. Điểm mới của Quyết định số 5631/QĐ-BYT so với Quyết định số 772/QĐ-BYT là nhấn mạnh 6 nhiệm vụ cốt lõi, làm rõ thêm những chỉ số đánh giá cân thực hiên và bổ sung các chỉ số khuyến khích thực hiện. Tuy nhiên, việc áp dụng các chỉ số đánh giá này vào thực tế còn nhiều điều khó khăn khi các chỉ số này chưa được hướng dẫn cụ thể cách tính, chuẩn hóa. Mục tiêu nghiên cứu thực hiện để khảo sát tình hình triển khai chương trình QLKS tại các cơ sở y tế trên địa bàn TPHCM năm 2020, nhằm cung cấp cái nhìn tổng quan về việc triển khai, từ đó đưa ra định hướng, giải pháp phù hợp.

\section{II. ĐỐI TƯỢNG VÀ PHƯƠNG PHÁP NGHIÊN CỨU}

2.1. Đối tượng nghiên cứu. Các cơ sở y tế (công lập và ngoài công lập) trên địa bàn thành phố Hồ Chí Minh.

2.2. Thời gian và địa điểm: Thực hiện từ 21/01/2021 đến 19/02/2021 để khảo sát tình hình triển khai hướng dẫn về chương trình quản lý kháng sinh của Bộ Y tế (Quyết định số 772/QĐ-BYT và Quyết định số 5631/QĐ-BYT).

\subsection{Phương pháp nghiên cứu}

2.3.1. Thiết kế nghiên cứu. Nghiên cứu mô tả cắt ngang.

2.3.2. Cỡ mẫu và phương pháp chọn mẫu. Nghiên cứu khảo sát được 57 cơ sở y tế trên địa bàn TPHCM, gồm 53 bệnh viện và 4 trung tâm y tế, với đa số là cơ sở y tế công lập (50/57 cơ sở).

2.3.3. Nội dung nghiên cứu. Nghiên cứu khảo sát sử dụng bộ câu hỏi được xây dựng căn cứ theo Quyết định số 772/QĐ-BYT và Quyết định số 5631/QĐ-BYT. Thông tin thu thập bao gồm: (1) thông tin cá nhân: giới tính, năm sinh, chức vụ; (2) thông tin bệnh viện: tỷ lệ chi phí sử dụng kháng sinh, thời điểm triển khai chương trình QLKS; (3) thông tin đánh giá về hoạt động quản lý sử dụng kháng sinh tại cơ sở; (4) thông tin đánh giá về tiêu chí của hoạt động quản lý sử dụng kháng sinh.

2.3.4. Phương pháp thu thập thông tin. 
Nghiên cứu đánh giá hiệu quả hoạt động quản lý sử dụng kháng sinh căn cứ vào phụ lục 7 ban hành kèm theo Quyết định số 772/QĐ-BYT. Nghiên cứu không đánh giá theo quyết định mới do thời điểm thực hiện nghiên cứu và thời điểm ban hành Quyết định số 5631/QĐ-BYT (thay thế Quyết định số 772/QĐ-BYT) là tương đối gần nhau (khoảng 1 tháng). Các thành phần đánh giá bao gồm: (1) Hoạt động hỗ trợ của ban lãnh đạo bệnh viện; (2) Trách nhiệm của bác sỹ: (3) Chuyên môn về dược; (4) Các hoạt động hố trợ sử dụng kháng sinh tối ưu; (5) Theo dõi: giám sát kê đơn, sử dụng kháng sinh và tính kháng kháng sinh; (6) Báo cáo thông tin về cải thiện sử dụng kháng sinh và tính kháng; (7) Đào tạo. Ngoài ra, các tiêu chí đánh giá tình hình sử dụng kháng sinh (khuyến cáo trong quyết định gồm 7 tiêu chí chất lượng và 2 tiêu chí định lượng) được nghiên cứu phân tích về tính cần thiết của từng tiêu chí (theo đánh giá của cá nhân khảo sát) và tình hình triển khai thực hiện phân tích tiêu chí đó tại cơ sở. Nghiên cứu đánh các nhóm thành phần thông qua việc phân tích phản hồi Có/Không của người khảo sát, kết quả được trình bày dưới dạng tần số (tỷ lệ \%). Điểm số của 7 thành phần chính là giá trị trung bình của tỷ lệ các thành phần phụ.

2.3.5. Phân tích dữ liệu. Kết quả được mô tả bằng bảng tần số, tỷ lệ phần trăm và phân tích bằng số liệu bằng Microsoft Excel.

2.3.6. Đạo đức nghiên cứu. Nghiên cứu được chấp thuận thực hiện bởi Sở $Y$ tế TPHCM thông qua Công văn số 479/SYT-NVD. Tất cả thông tin thu thập được mã hóa ẩn danh và chỉ phục vụ cho mục tiêu nghiên cứu.

\section{KẾT QUẢ NGHIÊN CỨU}

Qua khảo sát được 57 cơ sở y tế trên địa bàn TPHCM, chúng tôi ghi nhận có 41/57 cơ sở y tế có nội và ngoại khoa, 4/57 cơ sở y tế chỉ có ngoại khoa và 12/57 cơ sở chỉ có nội khoa. Đa số (93\%) cơ sở y tế có tỷ lệ chi phí kháng sinh trên tổng chi phí thuốc nằm trong khoảng dưới $30 \%$. Bốn bệnh viện ghi nhận tỷ lệ chi phí sử dụng kháng sinh tương đối cao (trên $30 \%$ ). Về việc triển khai QLKS, 48/57 cơ sở đã thực hiện triển khai, trong đó 47/48 cơ sở triển khai theo Quyết định số 772/QĐ-BYT. Chưa có cơ sở nào triển khai theo Quyết định số 5631/QĐ-BYT, nguyên nhân vì thời điểm ban hành của quyết định này (31/12/2020) tương đối gần với thời điểm khảo sát $(21 / 01 / 2021)$. Đối với các cơ sở chưa triển khai, một số lý do chính yếu được ghi nhận là thiếu hụt nguồn nhân lực, nguồn tài chính còn hạn chễ, công nghệ thông tin chưa sẵn sàng để đáp ứng đủ nhu cầu thực hiện.

Về đội ngũ nhân viên y tể tham gia hoạt động quản lý kháng sinh, bác sỹ và dược sĩ là hai nhóm nhận sự chủ lực tham gia hoạt động quản lý kháng sinh tại các cơ sở khảo sát. Chuyên gia vi sinh, quản lý chất lượng, kiểm soát nhiểm khuẩn, điêu dưỡng tham gia hoạt động ở mức độ trung bình với $58-74 \%$ cơ sở khảo sát ghi nhận. Nhân sự công nghệ thông tin $(40,0 \%)$ it tham gia và chuyên gia dịch tễ $(7,0 \%)$ là rất ít tham gia vào hoạt động quản lý kháng sinh.

Bảng 1. Đặc điểm mấu nghiên cứu $(n=57)$

\begin{tabular}{|c|c|}
\hline Đăc điếm & n (\%) \\
\hline Mô hình: Công lập & $50(88,0)$ \\
\hline Ngoài cồng lập & $7(12,0)$ \\
\hline Tuyến: Trung ương & $2(4,0)$ \\
\hline Tỉnh & $34(60,0)$ \\
\hline Quận huyện & $21(37,0)$ \\
\hline \multicolumn{2}{|l|}{ Quy mô theo giường bệnh* } \\
\hline 1 (từ 250 đến 350 giường) & $14(25,0)$ \\
\hline 2 (từ 400 đến trên 500 giường) & $16(28,0)$ \\
\hline 3 (trên 550 giường) & $22(39,0)$ \\
\hline \multicolumn{2}{|l|}{ Cơ sở có ngoại khoa/nội khoa } \\
\hline Nội khoa & $53(93,0)$ \\
\hline Ngoại khoa & $44(77,0)$ \\
\hline \multicolumn{2}{|l|}{ Phân nhóm bệnh viện } \\
\hline Đa khoa & $38(67,0)$ \\
\hline Chuyên khoa & $15(26,0)$ \\
\hline Trung tâm y tế & $4(7,0)$ \\
\hline \multicolumn{2}{|l|}{ Phân hạng bệnh viện } \\
\hline Hạng đặc biệt & $1(2,0)$ \\
\hline Hạng 1 & $23(40,0)$ \\
\hline Hạng 2 & $25(44,0)$ \\
\hline Hạng 3 & $4(7,0)$ \\
\hline Khác & $4(7,0)$ \\
\hline
\end{tabular}

Chi phí kháng sinh trên tổng chi phí thuốc

\begin{tabular}{|c|c|}
\hline & \\
\hline$>0-15 \%$ & $29(51,0)$ \\
\hline $16-30 \%$ & $24(42,0)$ \\
\hline $31-45 \%$ & $2(4,0)$ \\
\hline $46-60 \%$ & $2(4,0)$ \\
\hline Năm triến khai chương trình & \\
\hline 2013 & $2(2,0)$ \\
\hline 2016 & $15(31,0)$ \\
\hline 2017 & $10(21,0)$ \\
\hline 2018 & $14(29,0)$ \\
\hline 2019 & $7(15,0)$ \\
\hline Căn cứ triến khai chương trì & QLKS \\
\hline Quyết định số 772/QĐ-BYT & $47(99,98)$ \\
\hline Quyết định số 5631/QĐ-BYT & - \\
\hline Tự xây dựng & $1(0,02)$ \\
\hline Đội ngũ nhân viên y tế tham & \\
\hline Bác sĩ & $54(95,0 \%)$ \\
\hline Dược sĩ & $54(95,0 \%)$ \\
\hline
\end{tabular}




\begin{tabular}{|c|c|}
\hline Chuyên gia vi sinh & $33(58,0 \%)$ \\
\hline Chuyên gia dịch tế & $4(7,0 \%)$ \\
\hline Chuyên gia quản lý chất lượng & $35(61,0 \%)$ \\
\hline Chuyên gia kiếm soát nhiêmm khuấn & $42(74,0 \%)$ \\
\hline Điều dưỡng & $38(67,0 \%)$ \\
\hline Công nghệ thông tin & $23(40,0 \%)$ \\
\hline
\end{tabular}

*05 bệnh viện chưa ghi nhận được thông tin về số lượng giường bệnh

Đánh giá hiệu quả hoạt động quản lý sử dưng kháng sinh. Về tám nhóm thành phần để đánh giá hiệu quả hoạt động quản lý sử dụng kháng sinh, phân lớn các thành phần đã được các cơ sở đã thiết lập (trên $75 \%$ cơ sở). Trong đó, công tác theo dõi về giám sát kê đơn, sử dụng kháng sinh và tính kháng kháng sinh $(67 \%)$; và vai trò tham gia của bác sĩ vào các hoạt động quản lý kháng sinh ở mức trung bìnhcao (67\% cơ sở). Đồng thời, nguồn ngân sách hỗ trợ cho hoat động quản lý kháng sinh được thiết lập ở mức tâp tại các cơ sở (30\% cơ sở). Đánh giá sâu về các hoạt động triển khai, nghiên cứu ghi nhận một số hoạt động [chủ yếu liên quan đến vi sinh] chưa/không được triển khai thường xuyên, bao gồm: hoạt động liên quan đến báo cáo tình hình kháng thuốc, theo dõi tỷ lệ nhiễm khuẩn C.difficile, hệ thống cảnh báo tự động (cảnh báo trùng lặp hoạt chất khi kê đơn), báo cáo tình hình kháng thuốc. Các hoạt động còn lại được cơ sở thường xuyên hoặc luôn luôn triển khai.

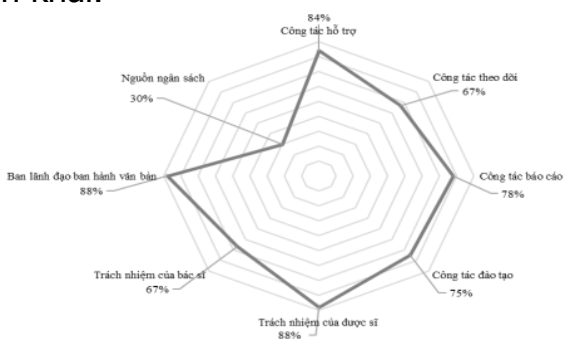

A

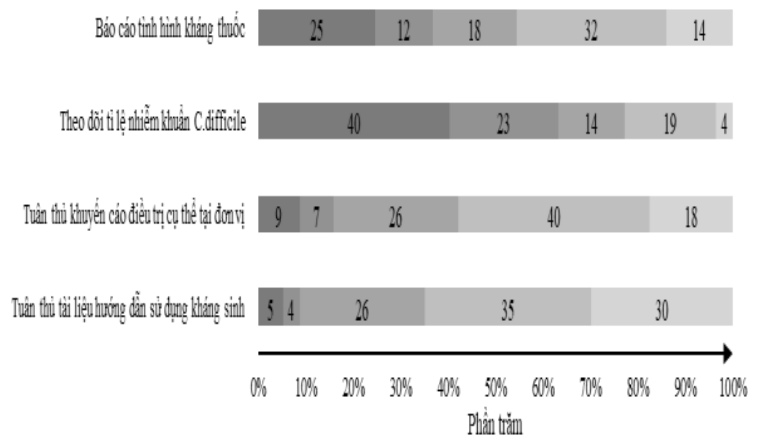

B

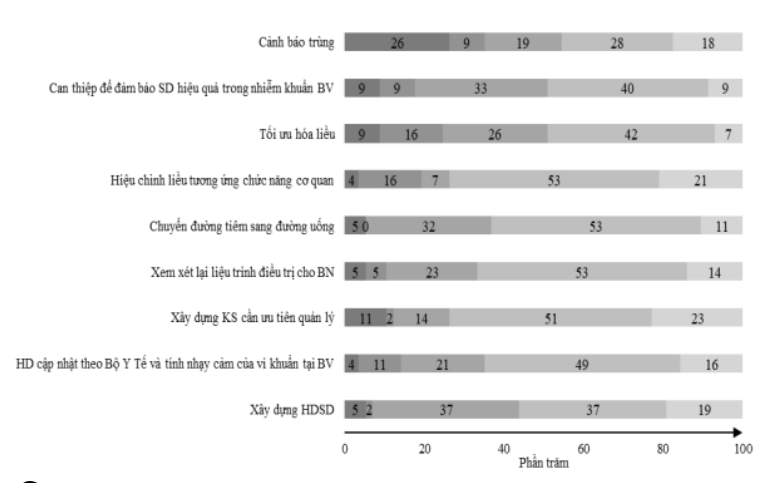

C
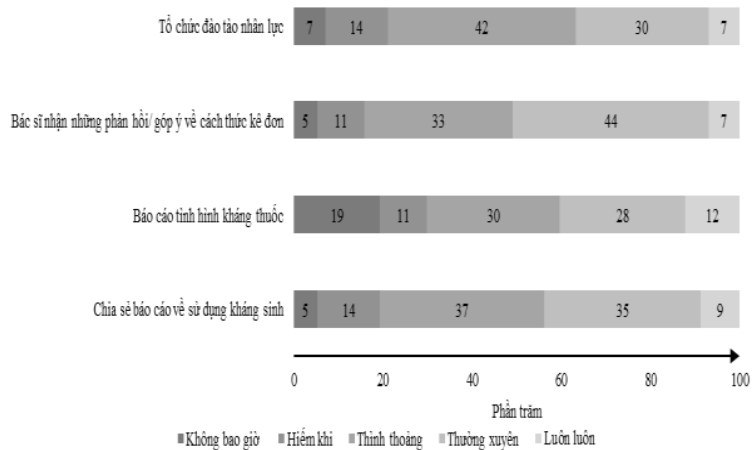

D

Hinh 1. Các công tác trong việc thực hiện hoạt động liên quan đến chương trinh QLKS. (A) Công tác theo dõi; (B) Công tác hỗ trợ; (C) Công tác báo cáo và đào tạo; (D) Các công tác và các hoạt động liên quan

Hình 1 trình bày kết quả đánh giá về các công tác trong việc thực hiện hoạt động quản lý sử dụng kháng sinh.

Bộ tiêu chí đánh giá tình hình quản lý sử dung kháng sinh. Nhìn chung, đa số ý kiên (43/57 cơ sở) đều cho rằng cần bổ sung một số tiêu chí phù hợp với quy mô, thực trạng của cơ sở. Bên cạnh đó, các cơ sở cũng đề xuất cần có những hướng dấn cu thể hơn về cách thu thập dữ liệu và phân tích cho các chỉ số như tỷ lệ chuyển kháng sinh đường tiêm sang đường uống, DOT, DDD, LOT. Quyết định số 772/QĐBYT đề xuất các chỉ tiêu đánh giá trên tinh thần khuyến khích thực hiện dựa vào tình hình, điều kiện của cơ sở. Đại đa sổ ý kiến đều cho rằng các chỉ số đều rất cần thiết cho chương trình QLKS, song thực tiễn áp dung thì có phần hạn chế, điển hình là hai chỉ số đo lường đều chiếm tì lệ thấp $(<50 \%)$. Nguồn lực bao gồm cả tài lực và nhân lực đều còn khá hạn hẹp dẫn đến sự thiếu liên kết khi thực hiện, đặc biệt là khi nguồn nhân lực CNTT còn thiếu, hệ thống CNTT chưa phát 
triển làm cho viêc triển khai các chỉ số đánh giá còn khó khăn. Kết quả khảo sát cho thấy mặc dù DOT và DDD là hai chỉ số đo lường số lượng, cần sự tính toán chính xác, nhanh chóng thì vấn còn thực hiện thủ công, chưa được vi tính hóa. Bên cạnh đó các chỉ số đang được ứng dụng CNTT tại bệnh viện là phân tích $A B C$, phân tích VEN, báo cáo $A D R, M E$ tuy nhiên vẫn là bán tự động.

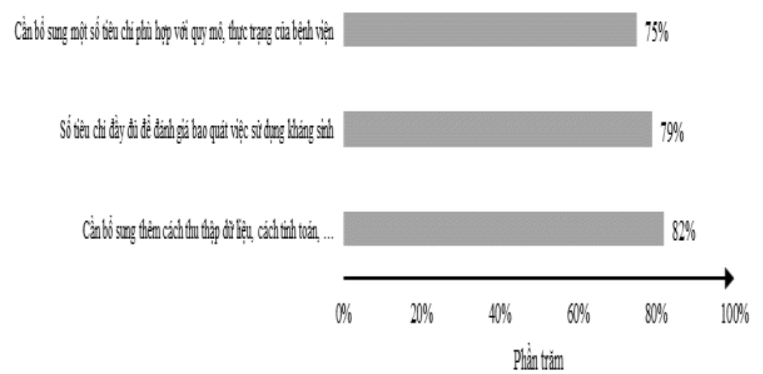

A

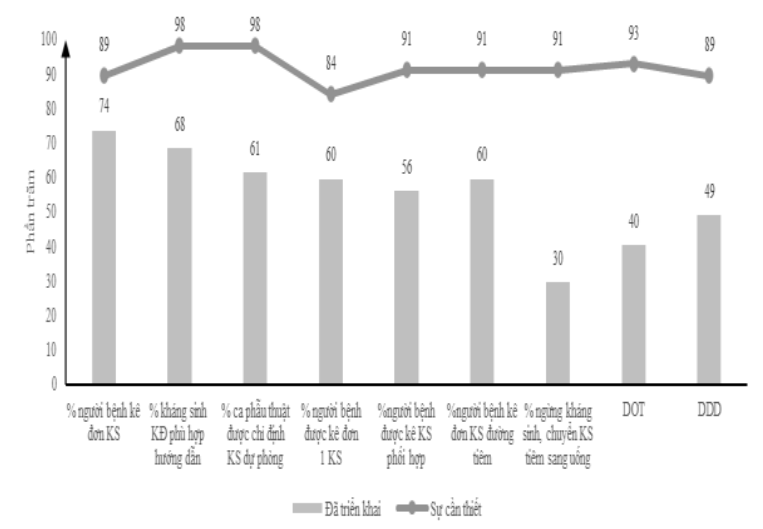

B

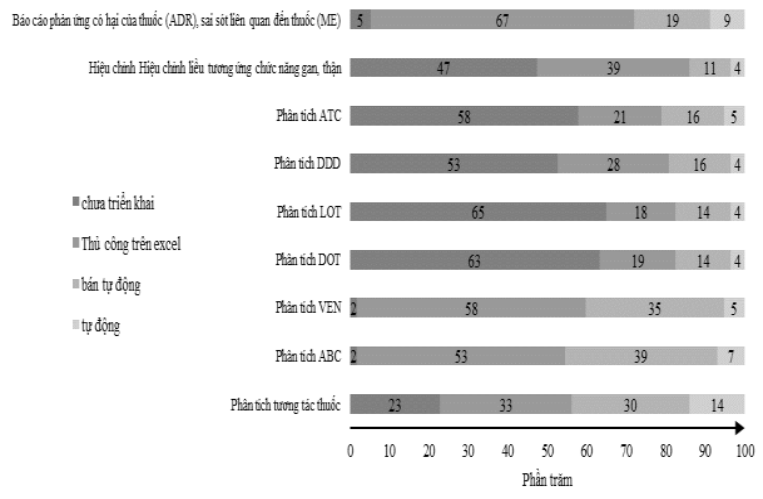

C

Hình 2. Tình hình triển khai các tiêu đánh giá tình hình quản lý sử dụng kháng sinh. (A) Đánh giá về tổng quát về các tiêu chí; (B) Đánh giá về sự cần thiết và thực trạng triển khai các tiêu chí; (C) Tình hình triển khai phân tích các tiêu chí

\section{BÀN LUẬN}

Tình hình triển khai hoạt động quản lý sử dung kháng sinh tai 57 cơ sở y tế trên đia bàn TPHCM đạt mức trên trình bình với điểm tổng thể là $63 / 100$, kết quả này tương đồng với kết quả của nghiên cứu trước đó tại TPHCM. [2] Đánh giá về giá trách nhiệm của bác sĩ, dược sĩ, ban lãnh đạo bệnh viện tại các cơ sở là rất cao. Tuy nhiên, nguồn ngân sách hỗ trợ là vấn đề mà các nhà quản trị bệnh viện cần quan tâm. Hiện nay, với cơ chế tự chủ đối với bệnh viện công lập theo Nghị định số 16/2015/NĐ-CP và 85/2012/NĐ-CP, bệnh viện công lập được chủ động huy động các nguồn lực ngoài ngân sách; chủ động trong chính sách đãi ngộ, thu hút cán bộ y tế, đội ngũ chuyên gia. [3],[4] Do dó, việc cải thiện một số thành phần trong hoạt động quản lý kháng sinh, đặc điểm là về nguồn ngân sách và đội ngũ chuyên gia [hiện đang thiếu chuyên gia dịch tễ] có thể từng bước khắc phục. Nghiên cứu ghi nhận bốn bệnh viện có chi phí sử dung kháng sinh từ $31 \%$ trờ lên so với tổng chí phí thuốc, điêu này hoàn toàn phù hợp vì mô hình bệnh tật của những cơ sở này chủ yếu là bệnh về tai-mũi-họng, bệnh lao và bênh HIV.Thông qua kết quả khảo sát có thể thây được thực tế rằng vai trò của chuyên gia dịch tế $(7 \%)$ và $\mathrm{CNTT}(40 \%)$ còn chưa được thể hiện rõ trong Ban quản lý kháng sinh. Việc đội ngũ CNTT chưa sẵn sàng để hỗ trợ hoạt động quản lý kháng sinh dẫn đến triển khai phân tích các tiêu chí đánh giá tình hình sử dụng kháng sinh còn mang tính thủ công và chưa một số công tác có tần suất triển khai thấp. Kết quả nghiên cứu tương tự với phân tích của tác giả Madiha Mushtaque và cộng sự thực hiện tại Karachi, Pakistan. [5]

Công tác hỗ trợ bao gồm các hoạt động như xem xét lại liệu trình điều trị của bệnh nhẩn và hỗ trợ hiệu chỉnh trong những trường hợp suy giảm chức năng của 1 số cớ quan (như gan, thận...), chuyển đổi kháng sinh đường tiêm/ truyền sang kháng sinh đường uống, thay thế/ ngừng kháng sinh khi cần. Xây dựng hướng dẫn sử dụng, đảm bảo mang tính cập nhập theo Bộ Y Tế và tính nhạy cảm của vi khuẩn tại bệnh viện. Sự phối hợp của các công tác, nhấn mạnh phần nguồn ngẩn sách đối với chương trình quản lý kháng sinh còn hạn hẹp. Trong khi đó công tác theo dõi bao gồm các hoạt động như là tuân thủ tài liệu hướng dẫn sử dụng kháng sinh, khuyến cáo điều trị cụ thể tại đợn vị, theo dõi tî lệ nhiễm khuẩn Clostridium difficile và báo cáo kịp thời tình hình kháng thuốc vẫn còn hạn chế hơn so 
với các công tác khác. Một trong lý do công tác theo dõi còn hạn chế một phần có thể do nguồn nhân lực chưa đủ đáp ứng cho vai trò này. Mặc dù đa số nhân thức được sự cần thiết của các tiêu chí đánh giá, việc triển khai thực hiện các tiêu chí này lại không đáp ứng được kỳ vọng đạt ra. Trong đó, chỉ có 1 trên 7 tiêu chí được trền $70 \%$ cơ sở thực hiện, ba tiêu chí về tỷ lệ chuyển kháng sinh tiểm sang uống (30\%), DOT (40\%) và $\mathrm{DDD}(49 \%)$ được nhìn nhận là khó thực hiện. Việc tự động hóa phân tích một số chỉ số thường quy như $A B C, A T C$ còn ít (dưới $5 \%$ ). Do đó, cần đầy manh ứng dụng CNTT hỗ trợ phân tích các tiêu chí từ đó giảm tải hoạt động cho nhân viên y tế và giúp đưa ra các quyết định điều trị hiệu quả hơn.

\section{KẾT LUẬN}

Thông qua việc khảo sát tình hình triển khai chương trình QLKS tại các cơ sở nhận thây rằng nguồn lực là vô cùng quan trọng. Các cơ sở cần đẩy mạnh ngân sách, cơ sở vật chất hơn nữa, đồng thời cần nguồn nhân lực không chỉ đủ vế số lượng mà còn phải cả về chất lượng tức là phải nắm bắt kịp thời, vận dụng được các chỉ số trong công tác thường quy. Điều này thì đòi hỏi công tác đào tạo nhân lực cần được chú trọng hơn nữa. Bên cạnh đó việc bổ sung thêm một số tiêu chí phù hợp với quy mô, thực trạng của cơ sở và có hướng dẫn cụ thể trong tính toán các chỉ số đo lượng, cách thu thập dữ liệu hiệu quả. Đồng thời cần đẩy mạnh áp dụng công nghệ thông tin vào quá trình thực hiện hơn nữa, sử dụng phần mềm tự động hóa để tiết kiệm thời gian, chi phí và chính xác hơn.

\section{Lờ' CẢM ƠN}

Nghiên cứu này được tài trợ bởi Sở Khoa Học và Công nghệ Thành phố Hồ Chí Minh (DOST HCMC) cho TS. Nguyễn Thị Hải Yến và ThS Huỳnh Phương Thảo tại Quyết định số 51/QĐ-SKHCN

\section{TÀI LIẸU THAM KHẢO}

1. N. Van Kinh, "Situation Analysis: Antibiotic Use and Resistance in Vietnam."

2. T.-H.-Y. Nguyen et al., "Implementation status of antimicrobial stewardship programs in hospitals: A quantitative analysis study in $\mathrm{Ho}$ Chi Minh city, Vietnam," Medpharmres, vol. 4, no. 2, pp. 34-39, 2020, doi: https://doi.org/ 10.32895/ UMP.MPR.4.2.5.

3. Chính phủ, "Nghị định 16/2015/NĐ-CP quy định cơ chế tự chủ của đơn vị sự nghiêp công lập," 2015.

4. Chính phủ, Nghị định số 85/2015/NĐ-CP về cơ chế hoat động, cớ chế tài chính đối với các đơn vị sự nghiệp y tế công lập và giá dịch vụ khám bệnh, chữa bểnh của các cở sở khám bệnh, chữa bệnh công lập. 2012.

5. M. Mushtaque, F. Khalid, A. A. Ishaqui, R. Masood, M. B. Maqsood, and I. N. Muhammad, "Hospital Antibiotic Stewardship Programs - Qualitative analysis of numerous hospitals in a developing country," Infect. Prev. Pract., vol. 1, no. 3, p. 100025, 2019, doi: https://doi.org/10.1016/j.infpip.2019.100025.

\section{KHẢO SÁT TÌNH TRANG THIẾU VITAMIN D Ở NGƯỜI BỆNH VIỀM KHỚP - CộT SỐNG}

\section{TÓM TẮT.}

Mục tiêu: Khảo sát tình trạng thiếu vitamin $D$ ở người bệnh viêm khớp - cột sống. Đối tượng và phương pháp nghiên cứu: nghiên cứu mổ tả cắt ngang trên 67 người bệnh được chẩn đoán viêm khớp - cột sống theo tiêu chuẩn của ASAS tại khoa Cơ Xưởng Khởp bệnh viện Bạch Mai. Thiếu hụt vitamin $D$ được xác định khi nồng độ 25(OH)D3 huyết thanh < $30 \mathrm{ng} / \mathrm{ml}$. Kết quả: Nồng độ vitamin $\mathrm{D}$ trung bình của nhóm bệnh nhân nghiên cứu là $26,1 \pm 6,72 \mathrm{ng} / \mathrm{ml}$, tỉ lệ bệnh nhân có thiêu hụt nồng độ vitamin $D$ là $64,2 \%$.

\footnotetext{
${ }^{1}$ Trường Đại học Y Dược Thái Bình

Bênh viên Đa khoa Tầm Anh

Chịu trách nhiệm chính: Ngô thị Hoài

Email: ngohoaiytb@gmail.com

Ngày nhận bài: 8.7.2021

Ngày phản biện khoa học: 3.9.2021

Ngày duyệt băi: 10.9.2021
}

\section{Ngô Thị Hoài ${ }^{1}$ Đặng Hồng Hoa ${ }^{2}$, Lê Minh Hiếu ${ }^{1}$}

Kết luận: Tình trạng thiếu vitamin D khá phổ biến ở bệnh nhân viêm khớp - cột sống.

Tư khóa: Vitamin D, viêm khớp - cột sống

\section{SUMMARY \\ SERVEY ON VITAMIN D DEFICIENCY IN SPONDYLOARTHRITIS PATIENTS}

Aims: determine the prevalence of vitamin D deficiency among patient spondyloarthritis. Methods: a cross study was conducted with 67 patients with spondyloarthritis at Department of Rheumatologie, Bach Mai hospital and E hospital. Vitamin D deficiency was defined as serum Vitamin $D<30 \mathrm{ng} / \mathrm{ml}$. Results: The average serum Vitamin $D$ is $26,1 \pm 6,72 \mathrm{ng} / \mathrm{ml}$, the prevalence of vitamin $\mathrm{D}$ deficiency is $64,2 \%$. Conclusion: Vitamin $D$ deficiency in patient spondyloarthritis is popular.

Keywords: Vitamin D; spondyloarthritis 